\title{
Melons: Safe Handling Practices for Consumers ${ }^{1}$
}

\author{
Amy Simonne ${ }^{2}$
}

Since most of us buy melons at the store or farmers market, it is easy to forget that most melons are grown on the ground. Watermelons, cantaloupe, and honeydew melon are the most popular varieties of melons in the United States. Because they are exposed to pests and microorganisms from dirt, it is very important to apply the best food safety practices before enjoying them.

Many people have gotten sick from eating poorly washed melons, particularly cantaloupes, which have been the source of several multistate foodborne illness outbreaks. For instance, in September/October 2012, 261 people in 24 states were infected as a result of a Salmonella outbreak caused by tainted cantaloupe grown in Indiana (http:// www.cdc.gov/salmonella/typhimurium-cantaloupe-08-12/ index.html). The previous year, cantaloupes grown on a Colorado farm led to a Listeriosis outbreak, infecting 84 Americans (http://www.cdc.gov/listeria/outbreaks/ cantaloupes-jensen-farms/093011/index.html). What can you do to prevent becoming ill from contaminated melons? Whether they are store bought or home grown, use these guidelines to select, prepare, and safely enjoy melons in your home.

\section{At the Store}

Select melons that have no imperfections, such as sunken or dark spots. These areas make it easier for bacteria to travel from the outside to the inside of the melon. If you notice anything on the melon that you suspect is mold, do not purchase it.

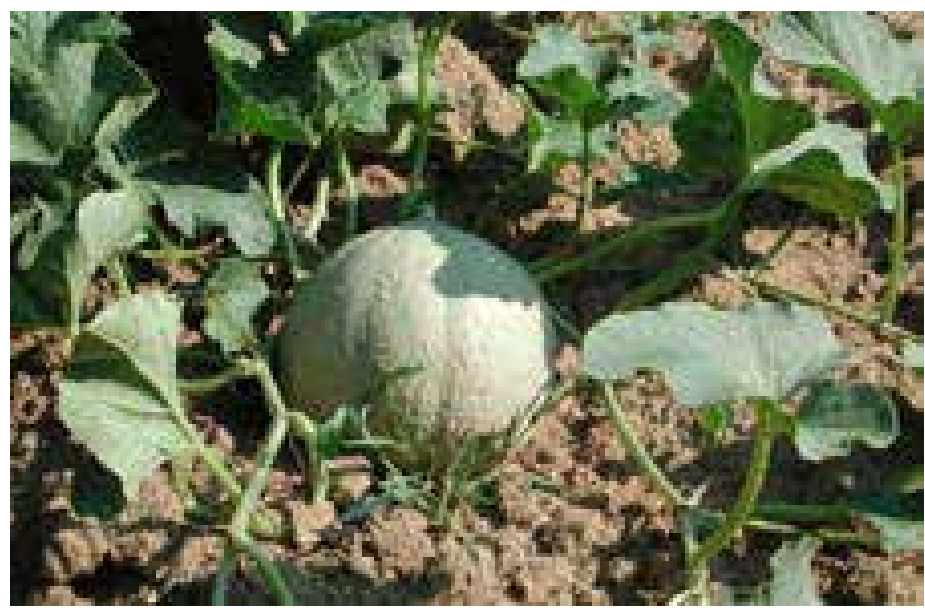

\section{Before Cutting Melons}

You may not think it is important to wash the outside of a melon, since you don't eat the tough outer part. When you slice the melon, bacteria on the outside of the melon are easily transferred to the inner edible area that you eat. Be sure to wash the outer surface of melons as described below. Wash your hands thoroughly with warm, soapy water before and after

- handling fresh produce;

- handling raw meat, poultry, or seafood;

- using the bathroom;

- changing diapers; or

- handling pets.

1. This publication is FCS8744, one of a series of the Department of Family, Youth and Community Sciences, Florida Cooperative Extension Service, Institute of Food and Agricultural Sciences, University of Florida. Adapted from the FDA Retail Food Safety Program Information Manual: Safe Handling Practices for Melons. First published November 2002. Latest revision June 2013. Please visit the EDIS website at http://edis.ifas.ufl.edu.

2. Amy Simonne, Ph.D., professor, Department of Family, Youth and Community Sciences, Florida Cooperative Extension Service, Institute of Food and Agricultural Sciences, University of Florida, Gainesville, FL 32611. 


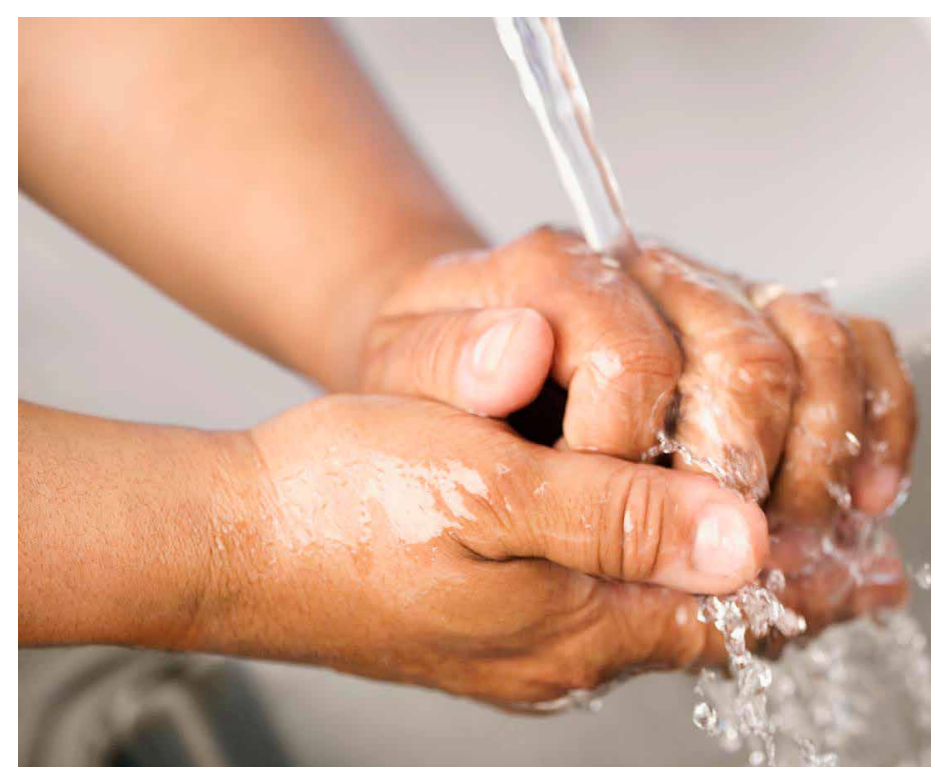

Wash the outer surface of the melon thoroughly with cool tap water to remove surface dirt. Scrub the melon with a clean produce brush. Dry the melon with a clean cloth or paper towel, and refrigerate until ready to cut. Using soap or detergent to clean your produce is not recommended. Produce washes are not harmful, but are not necessary.

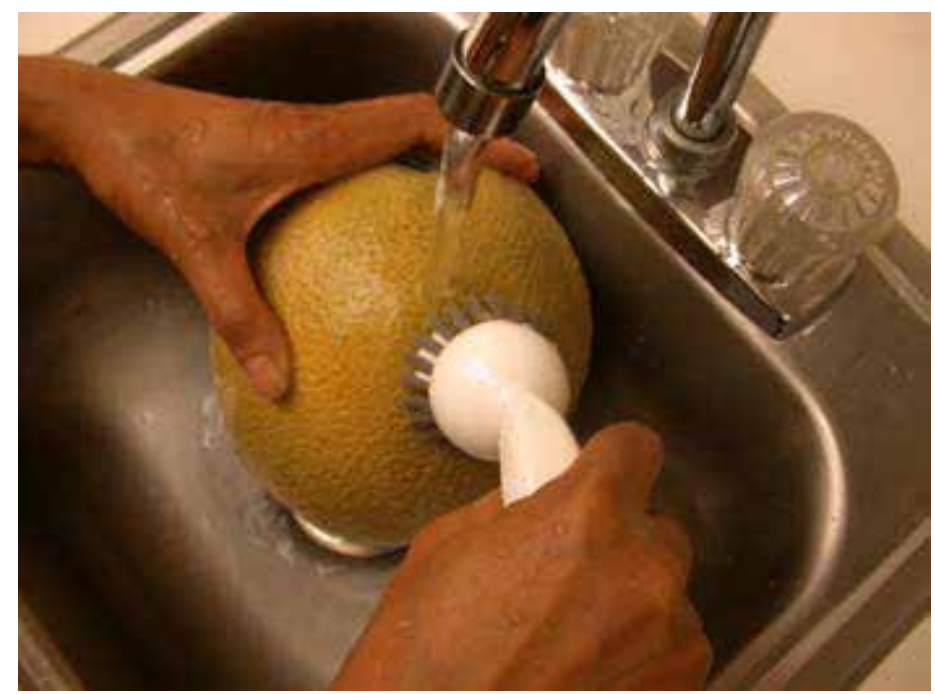

Wash equipment and utensils that will come in contact with cut melons (e.g., cutting boards, knives, etc.) thoroughly with hot, soapy water. Rinse, sanitize, and air-dry.

Sanitize your kitchen sink frequently to prevent a buildup of microbes.

\section{Sanitizing the Kitchen Sink, Countertops, and Cutting Boards}

Mix one teaspoon unscented chlorine bleach in one quart water.
To sanitize a sink, pour the mixture into the sink and let sit at least one minute and then rinse well with hot running water. You can sanitize a cutting board by submerging it in the sink when it is filled with the bleach solution. Let the cutting board soak for one minute and then rinse with hot running water.

Countertops can be sanitized by spreading the above solution on the counter and letting stand one minute before rinsing. Or you can use a sanitizing spray or wipes after the countertop is washed with soap and water for an additional safety measure.

\section{Cutting and Preparing Melons}

At home, it is acceptable to use clean bare hands to touch melons for your own consumption.

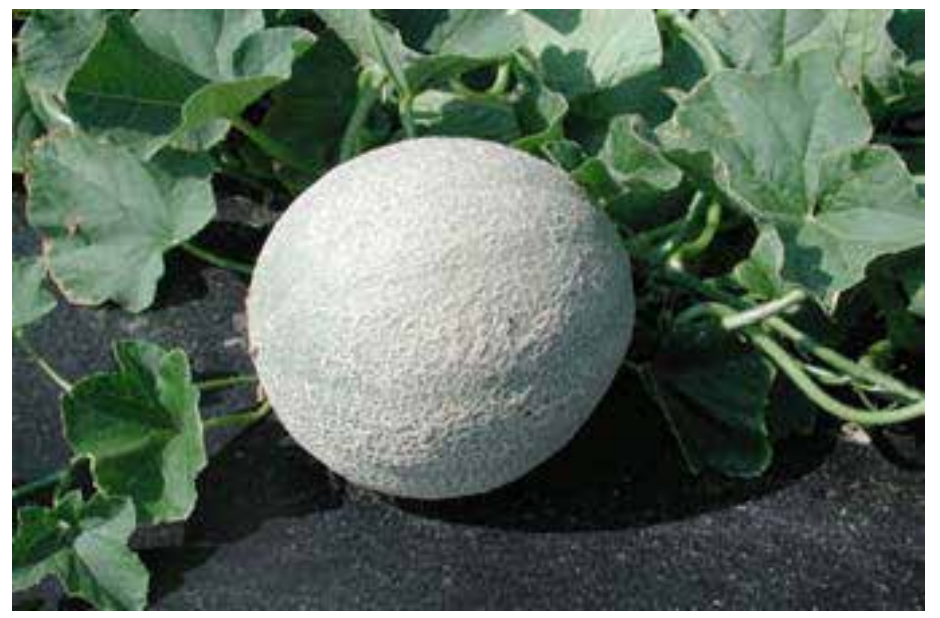

To further protect yourself and your family, you can use plastic gloves or appropriate utensils to touch cut melons.

Peel melon after washing to reduce chances of contamination from fruit surface.

\section{After Cutting Melons}

Wash your hands again after cutting the melon.

Store cut melons in a clean container in the refrigerator at a temperature of $41^{\circ} \mathrm{F}$ or below.

Label the container with the date. Cut melons that are not eaten within a week should be discarded.

Uneaten cut melons must be thrown away after four hours if they have not been refrigerated.

Note: Uncut melons do not need to be refrigerated. 


\section{In the Event of an Outbreak}

Contact your grocery store to see if your melon is from an affected farm.

If your melon may be contaminated

1. do not eat it;

2. dispose of the melon in a sealed plastic bag (to prevent consumption by animals); and

3. consult your health care provider if you think you have become ill as a result of contaminated food.

\section{For More Information}

Visit the Food and Drug Administration (FDA) website at http://www.fda.gov/Food/default.htm, call the FDA Outreach and Information Center at 1-888-SAFEFOOD, or visit the Centers for Disease Control and Prevention website at http://www.cdc.gov/foodsafety/. 